\title{
Dissolution rate of powdered quartz in acid solution
}

\author{
Hiroshi KamiYa ${ }^{1}$, Atsuko Ozaki ${ }^{1}$ and Masayuki Imahashi ${ }^{2}$ \\ Department of Chemistry, Nagoya Institute of Technology, Gokiso, Showa, Nagoya 466 $6^{1}$, \\ and Department of Chemistry, Toho University, Miyama, Funabashi, Chiba $274^{2}$, Japan
}

(Received October 13, 1973; in revised form November 21, 1973)

\begin{abstract}
The study reported in this paper concerns the role of salts in dissolution of powdered quartz. Kinetic dissolution experiment was carried out in acid media at 60 and $90^{\circ} \mathrm{C}$ to know the mechanism of acid alteration of rocks. The dissolution rate of silicon was accelerated by addition of such salts as sodium chloride and sodium sulfate in solution above about $\mathrm{pH} 2$ but not affected below about $\mathrm{pH} 2$. An accelerating effect of divalent sulfate ions was greater than that of monovalent chloride ions. Moreover, this effect became remarkably greater with increasing concentration of salts, increasing temperature and increasing $\mathrm{pH}$ value from 2 to 4 .
\end{abstract}

\section{INTRODUCTION}

The studies on the dissolution rate of solid silica were summarized by ILER (1955). Dissolution of silica is one of the most important reactions in geochemical processes, such as weathering and alteration of rocks. In areas near active volcanoes rocks are often altered by action of acid thermal solution or gases. Geological and mineralogical investigations have been carried out by many investigators. For example, LOVERING (1957) reported the precise study on the alteration of volcanic ash at Valley of Ten Thousand Smokes. But much remains to be learned of the reaction of parent materials with chemically active fluids.

Acid thermal alteration of wall rocks at the earth's surface should be considered as the reaction in open systems. Moreover, the reaction of silicate with solution is generally slow. In such reactions the equilibrium will not be reached. Accordingly, in alteration the reaction rate will be more significant than the equilibrium relation between minerals and their environments, as pointed out by GARRELS (1958).

Alteration processes consist of decomposition and rearrangement of original materials in the hydrothermal solution. The initial step of the reaction is the decomposition of minerals or the breakdown of chemical bonding in minerals.

While the alteration reaction is complicated because of numerous variables, one of the most important factors is the chemical character of active solution. Then, 
kinetic dissolution experiments on the decomposition of powdered quartz were carried out to examine the influence of the chemical character of active solutions. The study reported in this paper concerns mainly the role of salts in decomposition reaction of powdered quartz.

\section{EXPERIMENTAL}

As seen in Fig.1, only plastic equipments were used for this experiment to avoid contamination. A polyethylene bottle of $500 \mathrm{ml}$ fitted with a polyethylene condenser was placed in a constant temperature bath. The $\mathrm{pH}$ values and anion concentrations of leaching solutions were adjusted by addition of acid and salt solutions into distilled water. From 0.5 to $2 \mathrm{~g}$, but usually $1 \mathrm{~g}$ of powdered quartz (150 $200 \mathrm{mesh}$ ) was suspended in $300 \mathrm{ml}$ of the leaching solution, which was stirred continuously with a magnetic stirrer coated with polyethylene for $30 \mathrm{hr}$. The $\mathrm{pH}$ values of the leaching solution were measured in the range from 60 to $90^{\circ} \mathrm{C}$ with a high temperature $\mathrm{pH}$ meter, while little differences were found in the $\mathrm{pH}$ values of the initial

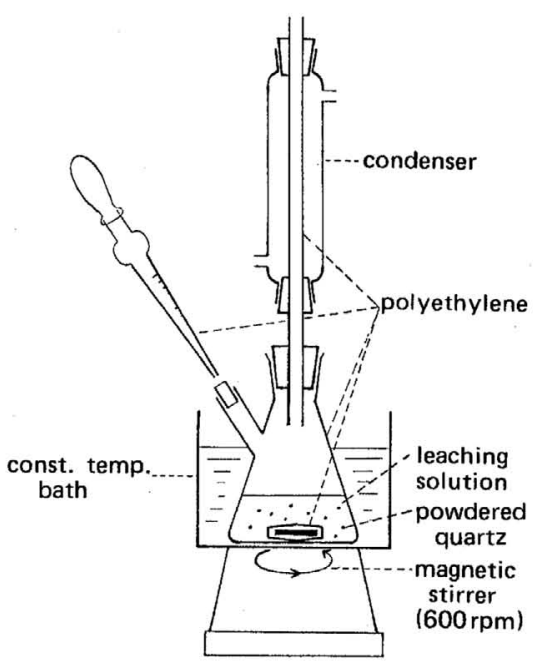

Fig.1. Equipment for experiment and final solutions in this experiment.

The dissolution rate of silicon was determined by periodically pipetting a $10 \mathrm{ml}$ aliquot from the bottle, by filtrating through a $0.45 \mu$ Millipore filter to remove powdered quartz and by chemically analyzing the filtrate, in which silicon was determined colorimetrically by the molybdenum blue method. The state of silicon dissolved in the solution will not be considered in the following discussion because it can not be known by this experiment.

\section{Results AND Discussion}

Dissolution curve of silicon The amounts of dissolved silicon at different times are shown in Figs. 2 to 5. As seen in Fig.2, below about pH 1, i.e., in strongly acid solution the data gave curved lines which imply the gradual decrease in the dissolution rate of silicon with time. More distinctly curved lines were obtained at $90^{\circ} \mathrm{C}$ than at $60^{\circ} \mathrm{C}$ and in hydrochloric acid of $\mathrm{pH} 0.2$ than of $\mathrm{pH} \mathrm{1.1.} \mathrm{The} \mathrm{dissolution} \mathrm{rate} \mathrm{of}$ silicon was not affected by the addition of salt in a strongly acid solution. 


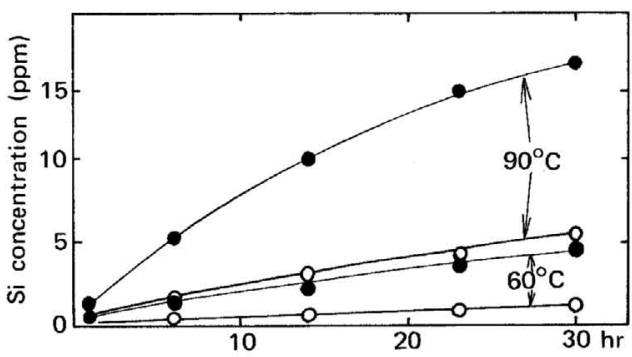

Fig.2. Concentration of dissolved $\mathrm{Si}$ in $\mathrm{HCl}$ at different times. $\mathrm{pH} \quad 0.2-$ $\mathrm{pH} 1.1-\mathrm{O}-$

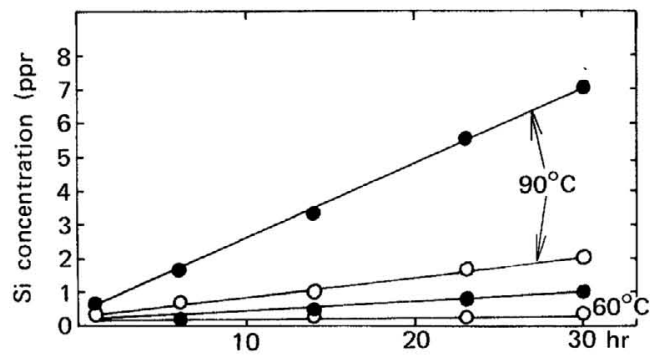

Fig.4. Concentration of dissolved Si in $0.5 \mathrm{M}$ $\mathrm{Cl}^{-}$solution adjusted with $\mathrm{HCl} \& \mathrm{NaCl}$ at different times. $\mathrm{pH} 2.1-\mathrm{O}-, \mathrm{pH} 3.2$

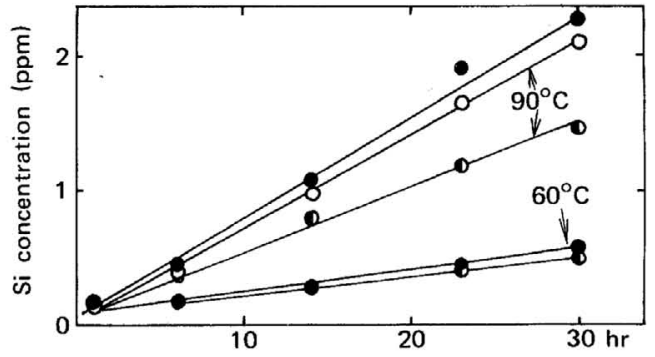

Fig.3. Concentration of dissolved $\mathrm{Si}$ in $\mathrm{HCl}$ at different time. $\mathrm{pH} 2.1-\mathrm{pH}$ $3.1-\mathrm{O}-\mathrm{pH} 4.2 \longrightarrow$ (Data of $\mathrm{pH} 3.1$ are plotted on the line of $\mathrm{pH} 4.2$ at $\left.60^{\circ} \mathrm{C}\right)$.

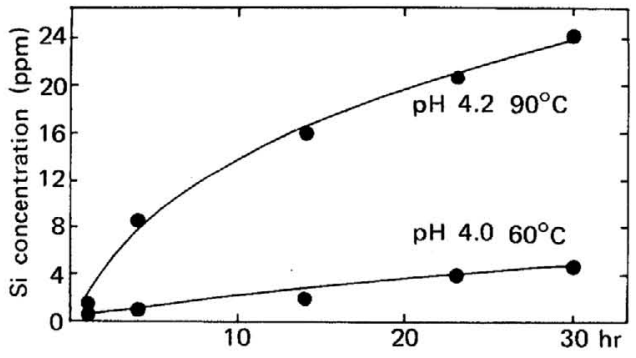

Fig.5. Concentration of dissolved $\mathrm{Si}$ in $0.5 \mathrm{M}$ $\mathrm{Cl}^{-}$solution adjusted with $\mathrm{HCl} \& \mathrm{NaCl}$ at different times.

In hydrochloric acid of about $\mathrm{pH} 2$ to 4 the data gave nearly straight lines as seen in Fig.3. In the range of about $\mathrm{pH} 2$ to 3 the dissolution rate was increased by the addition of sodium chloride though curved lines were not obtained as seen in Fig.4. As shown in Fig.5, at about pH 4 curved lines were obtained again with a remarkable increase in the dissolution rate by the addition of sodium chloride.

Approximate equation for dissolution rate of silicon

Figure 6 shows that the amount of dissolved silicon at any time was approximately proportional to the weight of powdered quartz suspended in the leaching solution. OKKERSE et al. (1961). reported the decrease in the surface area of silica gel due to the change in the surface: texture after heating the gel in solutions of different $\mathrm{pH}$ values.

Assuming that the change in the surface of powdered quartz brought about the depression of the dissolution rate with time, we get curved lines shown in Figs. 
2 and 5, and the following approximate equations:

$$
\begin{aligned}
m & =K_{1} S t+m_{0} \\
S & =S_{0}\left(1-K_{2} t\right) \\
m-m_{0} & =K_{1} S_{0} t-K_{1} K_{2} S_{0} t^{2}
\end{aligned}
$$

where $m$ and $m_{0}$ are the amounts of dissolved silicon at time $t$ and zero, $S$ and $S_{0}$ the surface area of powdered quartz at time $t$ and zero, and $K_{1}$ and $K_{2}$ the rate constants for dissolution of silicon and for decrease in apparent surface area, respectively. The amounts of rapidly dissolved silicon at the initial stage is $m_{0}$ and appears as an intercept on the data plot. Therefore, $m_{0}$ was obtained from an intercept of the dissolution curve on the $y$-axis.

As the surface area of powdered quartz was not measured in this experiment, $K_{1} S_{0}$, which represents the dissolution rate at time zero, will be used in the following discussion.

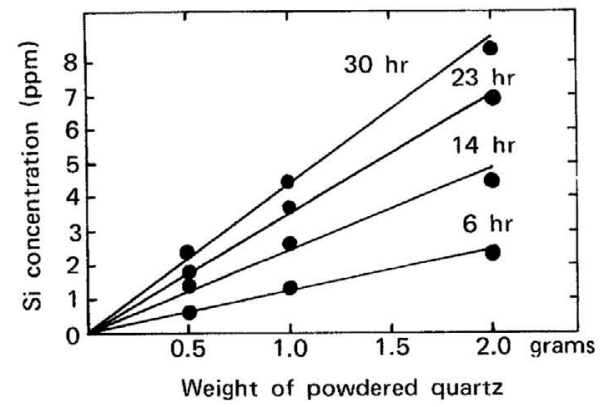

Fig.6. Concentration of dissolved $\mathrm{Si}$ at different times when powdered quartz of 0.5 , 1.0 and $2.0 \mathrm{~g}$ were suspended in $\mathrm{HCl}$ of $\mathrm{pH}$ 1.1 at $90^{\circ} \mathrm{C}$.

Influence of $p H$, temperature and salts

Figure 7 shows $K_{1} S_{0}$ in the solution of different chloride ion concentrations at different $\mathrm{pH}$ values at $90^{\circ} \mathrm{C}$. ILER (1955) summarized that sodium chloride greatly accelerated the formation of soluble silica

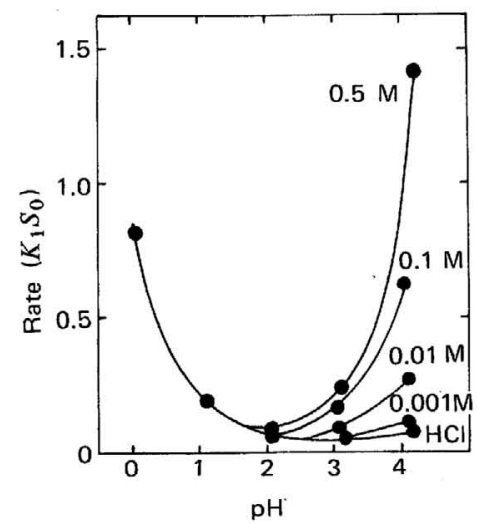

Fig.7. Apparent rate at different $\mathrm{pH}$ values. Influence of $\mathrm{Cl}^{-}$at $90^{\circ} \mathrm{C}$.

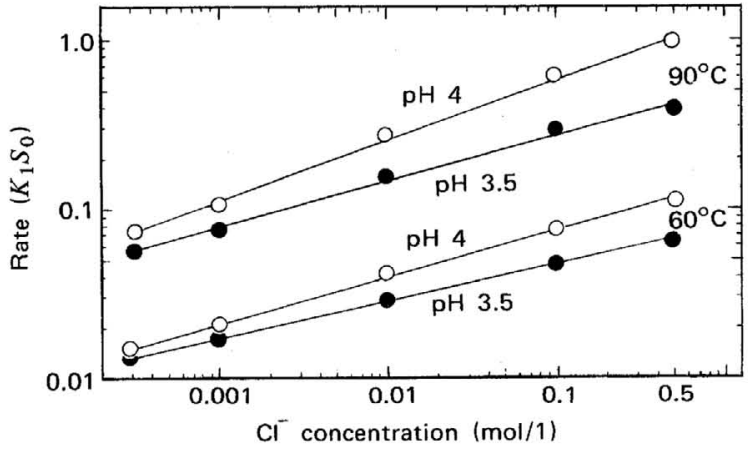

Fig.8. Plot of apparent rate $v$. chloride concentration $\mathrm{pH} 3.5-\bullet-, \mathrm{pH} 4-\mathrm{O}-$ 
from colloidal silica. In this experiment the dissolution rate was accelerated above about $\mathrm{pH} 2$ but not below about $\mathrm{pH} 2$, with increasing concentration of chloride ions. Moreover, this figure shows that an accelerating effect by chloride ions becomes remarkably greater with increasing $\mathrm{pH}$ values from 2 to 4 .

Figure 8 shows the approximately linear relation between the logarithm of $K_{1} S_{0}$ and the logarithm of chloride ion concentration. As seen in this figure, the increase in chloride ion concentration, the increase in $\mathrm{pH}$ value and the rise of temperature accelerated the dissolution rate of silicon.

Figures 9 and 10 show that the dissolution of silicon was catalyzed by sulfate ions as well as chloride ions and that the catalytic activity of divalent sulfate ions was higher than that of the monovalent chloride ions.

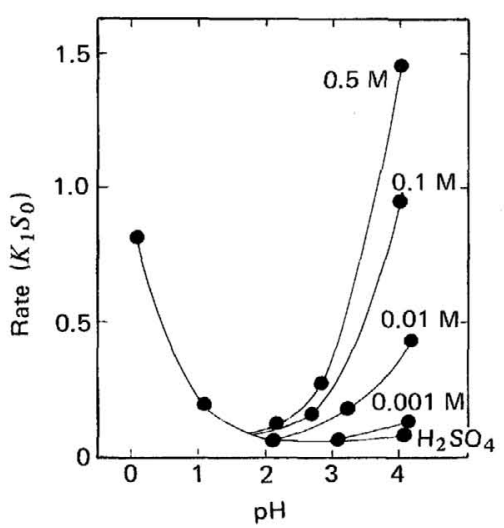

Fig.9. Apparent rate at different $\mathrm{pH}$ values. Influence of $\mathrm{SO}^{2-}$ at $90^{\circ} \mathrm{C}$.

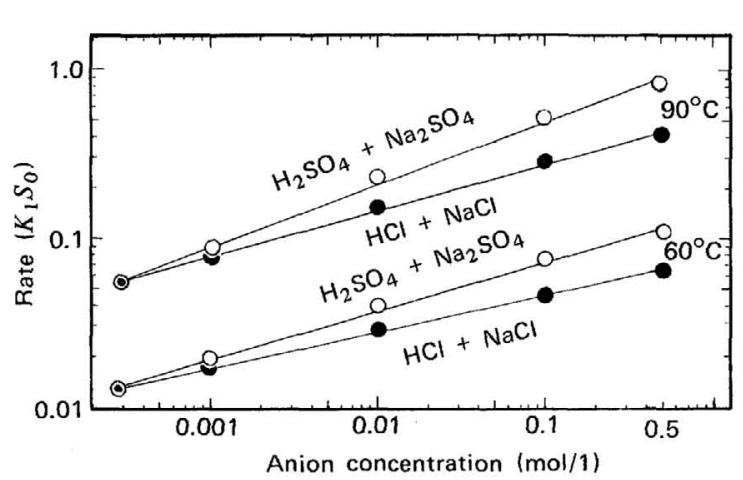

Fig.10. Plot of apparent rate $v$. anion concentration at $\mathrm{pH} 3.5, \quad \mathrm{H}_{2} \mathrm{SO}_{4}+\mathrm{Na}_{2} \mathrm{SO}_{4}$

As is generally known, water molecules tend to react as ligands with a number of cations and to form complexes. Since anions, such as chloride and sulfate ions which are abundant in the hydrothermal solution, are also ligands, it is reasonable. to expect that they behave in much the same way as water molecules. In this way chloride and sulfate ions as catalysts promote undoubtedly the breakdown of chemical bonds in the original minerals, which might facilitate the rearrangement to more stable structures under the new conditions.

\section{REFERENCES}

GARRELS, R. M. (1958) Rate of geochemical reactions at low temperatures and pressures. Researches in geochemistry. Ed. P. H. ABELSON. John Wiley, New York. pp. 33-36.

ILER, R. K. (1955) The colloid chemistry of silica and silicates. Cornell Univ. Press, Ithaca, N.Y. pp. 13-15.

LOVERING, T. S. (1957) Halogen acid alteration of ash at fumarole No.1, Valley of Ten Thou- 
sand Smokes, Alaska. Bull. Geol. Soc. Am. 68, 1585-1604.

OKKERSE, C. and DE BOER, J. H. (1961) Reactivity of amorphous silica in aqueous solutions. Reactivity of solids (Proc. 4th Intl. Symp. on the reactivity of solids). Ed. J. H. DE BOER et al. Elsevier, Amsterdam. pp. 240-248. 